\title{
The consumption/wealth and book/market ratios in a dynamic asset pricing contex
}

\author{
Belén Nieto* • Rosa Rodríguez**
}

\begin{abstract}
This paper addresses new insights into the predictability of financial returns. In particular, we analyze two aspects of the controversial forecasting literature. On the one hand, we demonstrate a positive and contemporaneous link between aggregate book/market and consumption/wealth ratios. On the other hand, we show that real estate and human capital, as the present value of all future salaries, are key components of the consumption/wealth ratio in Spain. Specifically, we find that the cointegrating residuals of consumption, asset holdings, real estate holdings, and our measure of human capital provide a better forecast of future returns than does the standard proxy of the consumption/wealth ratio. This result is important because it clarifies the importance of country-specific components of wealth for cases in which the consumption/wealth ratio is employed as an instrument in conditional asset pricing models.
\end{abstract}

Keywords Stock markets · Predictability · Consumption · Aggregate wealth · Book/market

\footnotetext{
* Financial support from the Ministerio de Ciencia y Tecnología grant SEJ2005-09372 is gratefully acknowledged.

** Financial support from the Ministerio de Ciencia y Tecnología grant SEC2003-06457 is gratefully acknowledged.

B. Nieto

Universidad de Alicante, Departamento de Economía Financiera Contabilidad y Marketing,

Alicante, Spain

e-mail: belen.nieto@ua.es

R. Rodríguez $(\varangle)$

Universidad Carlos III de Madrid, Departamento de Economía de la Empresa, Madrid, Spain

e-mail: rrlopez@emp.uc3m.es
} 


\section{Introduction}

Recent empirical evidence seems to suggest that returns on financial assets are relatively predictable. Thirty years ago such a statement would have been interpreted as a rejection of market efficiency. However, modern financial economics suggest that other rational factors such as time-varying expected returns due to changing business conditions could generate predictability. Many articles document this predictability using macroeconomic and past financial information such as lagged returns, output variables and inflation, dividend yield, short-term interest rates, spreads of interest rates, and book/market ratios ${ }^{1}$.

In recent years, controversy has developed over the extent to which financial ratios contain information about returns. During the 1990s, the US economy experienced dramatic changes in corporate financial policy and a striking increase in stock prices. Moreover, bias corrections employed in the significance hypothesis tests due to the persistence of financial ratios have cast some doubts on the predictive power of these variables. However, Lewellen (2004) has recently demonstrated that the previous bias corrections used in the literature substantially understate the predictive power of financial ratios - in particular, that aggregate book/market has been able to predict market returns in the US economy over the past 40 years.

On the macroeconomic side, Lettau and Ludvigson (2001a) find that aggregate consumption, asset holdings, and labor income share a common long-term trend, but may deviate one from another in the short term. They use the cointegrating residuals of these variables as a proxy for the consumption-aggregate wealth ratio - namely cay. Their results show that this variable captures a relatively large proportion of the variability of future returns for the US market, despite the fact that consumption, labor income, and asset holdings individually bear little relationship to future stock returns ${ }^{2}$. The success of this new instrumental variable is clear, as it has become the key predictor in the most recent asset pricing applications, in which other methods have enjoyed little success ${ }^{3}$. The reason is easy to understand. Given the connection between predictability in time series and the cross section of stock returns, lagged instruments that have been shown to predict market returns are natural conditioning variables for testing asset pricing models in the cross section.

It is interesting to note that the two predicting ratios seem to be based on very different foundations. The consumption/wealth ratio is closely related to real conditions, whereas book/market is directly associated with the financial

\footnotetext{
1 The following are merely samples of the extensive research on predictability of returns: Campbell and Shiller (1988); Chan et al. (1995), Davis (1994), Fama and French (1988a,b, 1998), Hodrick (1992), Keim and Stambaugh (1986), Kothari and Shanken (1997), Nieto (2002), Pontiff and Schall (1999), Poterba and Summers (1988), Rodrguez et al. (2002), and Lewellen (2004).

2 Gao and Huang 2004 also provide evidence on the behavior of cay forecasting stock market returns for the UK and Japan.

3 See Lettau and Ludvigson (2001b,c), Hodrick and Zhang (2001), Santos and Veronesi (2004), among others.
} 
conditions of the economy. We argue that there is a connection between these two sides of the economy and that these two ratios must therefore be related to some degree. Moreover, an analysis of the relationship between these ratios should facilitate our understanding of the conflicting issues regarding conditional asset pricing literature and the priced risk factors employed in unconditional models. Hence, the first objective of this paper is to study the common information shared by the book/market and consumption/wealth ratios that allow them both to forecast stock returns. In this sense, we argue that the two ratios share a common trend, which may be the reason behind their forecasting ability over long horizons, as found in previous literature. This intuition seems reasonable once we realize that the book value of a firm can be seen as an indicator of future cash flows, allowing it to play the same role as dividends. Under an accounting principle that relates book values to nondistributed earnings, we are able to obtain a theoretical expression that justifies both the forecasting power of the book/market variable and its link with the consumption/wealth ratio.

The second objective of this article is to estimate a proxy for the consumption/wealth ratio for the Spanish economy. We report that, when using the proxy proposed by Lettau and Ludvigson (2001a), this variable has limited power to forecast quarterly returns in the Spanish market for our sampling period. However, when we improve the measure of wealth by adding real estate and a new measure of human capital based on the present value of future salaries, we find interesting empirical evidence. First, we show that this proxy is able to weakly forecast returns as well as the book/market $\mathrm{ratio}^{4}$. But the latter presents the inconvenience of its high persistence. Once the persistence of the book/market regressor is corrected by the method developed by Amihud and Hurvich (2004), the only significant variable in forecasting regressions is our proxy of the consumption/wealth ratio. This suggests that the proper use of cay as a state variable in asset pricing models should account for real estate and human capital rather than labor income.

The remainder of our article is organized as follows. In section "Book/market ratio, consumption/wealth ratio, and stock market prices", we explain why book/market and consumption/wealth ratios forecast returns and present a contemporaneous and positive relationship between them. In section "The proxy for the consumption/wealth ratio", we compute the proxy for the consumption/wealth ratio (cay) for the Spanish case and check its ability to forecast returns and consumption-growth. Section "New approach to estimate the consumption/wealth ratio" presents our views on the importance of adequately measuring the components of wealth. We propose an improved proxy for cay, then repeat the forecasting regressions. A robustness exercise with a longer series is presented in section "Robustness", and section "Conclusion" contains our conclusions.

\footnotetext{
4 Using the equally weighted market index, both our new proxy and book/market seem to have a similar forecasting ability. However, even before any adjustment, when the value-weighted market index is used, the only significant predictor is our new proxy for consumption/wealth ratio.
} 


\section{Book/market ratio, consumption/wealth ratio, and stock market prices}

Since the work of Rosenberg et al. (1985), the empirical literature has shown how the stocks of firms with high book/market ratios offer higher average returns (value effect). A variety of explanations are discussed in the literature, including arguments such as a sample-specific effect (Black 1993; MacKinlay 1995), the irrational behavior of investors (DeBondt and Thaler 1987; Lakonishok et al. 1994), and arguments of risk due to aggregate factors (Fama and French 1993, 1996, 1998) or characteristics (Daniel and Titman 1997). In any case, researchers have found evidence in favor of the value effect across different sample periods (Davis 1994; Davis et al. 2000) and in many different countries (Chan et al. 1991; Capaul et al. 1993; Fama and French 1998; Liew and Vassalou 2000). If, indeed, the book/market ratio contains information about future stock returns, it may seem reasonable to use it as a state variable.

Lettau and Ludvigson (2001a) argue that short-run deviations from the longrun equilibrium relationship between consumption and aggregate wealth, as measured by financial and labor income, are a key determinant of the dynamics of asset returns. In particular, they show that market excess return is expected to be predictable and should present a mean-reverting behavior to match the relatively smooth behavior of consumption and labor income. Their proxy for the $\log$ consumption/wealth ratio provides a significant forecasting ability for excess returns over long horizons ${ }^{5}$. This is important because it links macroeconomic conditions during the business cycle with the behavior of financial markets, which may have relevant implications for understanding the price of economic fluctuations.

Given these two apparently unrelated results, a new question arises: Do the two variables share common information? Let us discuss the intuitive and theoretical arguments behind this question.

Why do the book/market and consumption/wealth ratios forecast returns?

In principle, dividends are the cash flows that investors expect for holding stocks. The value that the investor places on shares depends on these future cash flows. Let us assume that the shares belong to a firm that never pays dividends. The investor does not expect to obtain these flows, but the price of the stock is not zero because the nondistributed earnings may be considered as a proxy for expectations of future cash flows. As nondistributed earnings today increase the book value of the firm today, an increase in book value is associated with higher expected future payoffs and an increase in the expected return on the stock ${ }^{6}$. In this way, we can justify a positive and high contemporaneous correlation

\footnotetext{
5 See Brennan and Xia (2002) and Lettau and Ludvigson (2002) for a debate on this issue. In any case, cay has proven to be a successful instrument in testing conditional asset pricing models as in Lettau and Ludvigson (2001b) and Hodrick and Zhang (2001).

6 The book value at time $t$ contains the nondistributed earnings of that period.
} 
between consumption and book value: Higher expected future wealth produces an increase in the proportion of wealth consumed today. This statement provides the basis for the use of this financial ratio as a macroeconomic variable, and we now present theoretical support for this reasoning.

The idea relies on the accounting relationship between dividends and book values. If we assume that the dividend/price ratio does not work according to theory due to a non-stable corporate dividend policy, a relationship between that variable and the book/market ratio permits the latter to assume the role of the former. This reasoning is in line with that presented by Ohlson (1995), Feltham and Ohlson (1995), Vuolteenaho (2000), and Cohen et al. (2001).

Following Vuolteenaho (2000), under the assumption that the book/market ratio does not behave explosively, and using the accounting principle, we can approximate the book/market ratio as an infinite discounted sum of future stock returns, profitability, and the dividend/book ratio. In this way, we can justify the power of the book/market ratio in predicting returns.

Let $P_{t}$ be the market stock price at time $t$, and $D_{t}$ the dividends paid by the market at time $t$. From the definition of the market return $\left(R_{m t+1}\right)$, we know that

$$
1+R_{m t+1}=\frac{P_{t+1}+D_{t+1}}{P_{t}} .
$$

Taking logs in (1), and using a first-order Taylor expansion around the mean of the dividend/price ratio, we can write the log stock return as

$$
r_{m t+1} \cong K_{d}+\Delta d_{t+1}+\left(d_{t}-p_{t}\right)-\rho_{d}\left(d_{t+1}-p_{t+1}\right),
$$

where $K_{d}$ is a constant; each lower case variable denotes the log of the corresponding variable, and $\rho_{d}=\bar{P} /(\bar{P}+\bar{D})$.

On the other hand, we define the return on equity from $t$ to $t+1$ as the ratio between earnings in period $t+1\left(X_{\mathrm{t}+1}\right)$ and the book value in period $t(B t)$. The corresponding log return on equity is

$$
e_{t+1}=\log \left(1+\frac{X_{t+1}}{B_{t}}\right)
$$

We first assume that clean-surplus accounting is satisfied - that the book value in period $t+1$ equals the book value of the last period plus earnings less dividends,

$$
B_{t+1}-B_{t}=X_{t+1}-D_{t+1} .
$$

By combining Eqs. (2) and (3), and using a first-order Taylor expansion around the mean of the dividend/book ratio, we can approximate the log return on equity as a linear function of that ratio,

$$
e_{t+1} \cong K_{b}-\rho_{b}\left(d_{t+1}-b_{t+1}\right)+\Delta d_{t+1}+\left(d_{t}-b_{t}\right),
$$


where $K_{b}$ is a constant and $\rho_{b}=\bar{B} /(\bar{B}+\bar{D})$.

Subtracting (2) from (5) yields an equation that relates divergences between market and accounting returns to changes in the lagged book/market ratio and to the contemporaneous dividend/book and dividend/price ratios,

$$
e_{t+1}-r_{m t+1}=K_{b d}-\left(b_{t}-p_{t}\right)-\rho_{b}\left(d_{t+1}-b_{t+1}\right)+\rho_{d}\left(d_{t+1}-p_{t+1}\right),
$$

where $K_{b d}=K_{b}-K_{d}$.

Equation (6) is a linear difference relationship for the log market price. Solving forward and taking conditional expectations at time $t$, it is possible to express the book/market ratio as an infinite discounted sum of future market returns and accounting returns, thus showing that the book/market variable contains information about future expected returns,

$$
\begin{aligned}
b_{t}-p_{t}= & \frac{K_{b d}}{1-\rho_{d}} \\
& +E_{t}\left[\sum_{j=0}^{\infty} \rho_{d}^{j}\left(r_{m t+1+j}-e_{t+1+j}-\left(\rho_{b}-\rho_{d}\right)\left(d_{t+1+j}-b_{t+1+j}\right)\right)\right]
\end{aligned}
$$

where the operator $E_{t}$ denotes mathematical expectation conditional on information available at $t$.

This approximate equation for the book/market ratio (7) indicates that this ratio is high when investors expect high future market returns, low future returns on equity, or changes in the proportion in which earnings are distributed. If the mean of the ratio between book value and dividends is greater than the mean of the dividend/price ratio, an increase in the book/market ratio today is associated with a decrease in the fraction of earnings paid as dividends in the future. But if the dividend/price ratio is greater than the mean of the book/dividend ratio, a high book/market ratio today is associated with an increase in the proportion of distributed future earnings.

Observe the similarity between this equation and the one obtained by Campbell (1993) from the intertemporal budget constraint of the representative investor, assuming that the consumption/wealth aggregate ratio is stationary. Taking a first-order Taylor expansion around the mean of the log of the consumption/wealth ratio, the budget constraint may be approximated by

$$
\Delta w_{t+1} \approx r_{m t+1}+K_{c}+\left(1-\frac{1}{\rho_{c}}\right)\left(c_{t}-w_{t}\right)
$$

where $w_{t}$ is the log of the aggregate wealth in time $\mathrm{t}, c_{t}$ indicates the log of the aggregate consumption in $\mathrm{t}, \rho_{c} \equiv 1-\exp (\bar{c}-\bar{w})$, and $K_{c}$ is a constant.

Finally, combining (8) with the trivial equality $\Delta w_{t+1}=\Delta c_{t+1}\left(-\Delta\left(c_{t+1}-\right.\right.$ $\left.w_{t+1}\right)$, solving the resulting difference equation forward, and taking expectations, we can write 


$$
c_{t}-w_{t}=E_{t}\left[\sum_{j=1}^{\infty} \rho_{c}^{j}\left(r_{m t+j}-\Delta c_{t+j}\right)\right]+\frac{\rho_{c} K_{c}}{1-\rho_{c}} .
$$

Equation (9) specifies that if the consumption/wealth ratio is high, then the agent must expect high returns on future wealth or low consumption growth rates. It also implies that if the consumption/wealth ratio is not constant, it must predict changes in returns or consumption.

Therefore, in the same way that the consumption/wealth ratio captures the difference between future returns and future consumption growth rates (Eq. 9), the book/market ratio can be used to explain the difference between future stock returns and future returns on equity (Eq. 7). In that sense, we argue that these two ratios share common information, given that they both forecast returns theoretically. Under this framework, it is reasonable to believe that there must be some positive and contemporaneous relationship between the book/market ratio and the consumption/wealth ratio. The next subsection shows such a relationship.

\section{Do book/market and consumption/wealth ratios share common information?}

The definition of returns as given by Eq. (2) suggests that the dividend/price ratio at time $t$ contains information about market returns in the next period. Similarly, the budget constraint in (8) also suggests that the consumption/wealth ratio contains information about the future market return. By combining expressions (2) and (8), we find an equation that relates the consumption/wealth ratio at time $t$ to the dividend/price ratio in the next period,

$$
\begin{gathered}
c_{t}-w_{t}=\left(\frac{\rho_{c}}{1-\rho_{c}}\right)\left[K_{c d}-\Delta w_{t+1}+\left(p_{t+1}-p_{t}\right)\right] \\
+\frac{\rho_{c}\left(1-\rho_{d}\right)}{\left(1-\rho_{c}\right)}\left(d_{t+1}-p_{t+1}\right),
\end{gathered}
$$

where $K_{c d}=K_{c}+K_{d}$.

The above equation indicates that the representative agent would be able to consume more today relative to his wealth as long as the future market price is higher than the current price, and/or there is a higher future dividend yield. Otherwise, his wealth in the next period would be higher than his current wealth because current consumption does not increase relative to wealth.

Under clean-surplus accounting, which relates the book/price ratio today and the dividend/price ratio in the next period (Eq. 6), we can express Eq. (10) in terms of the book/market ratio instead of the dividend/price ratio, 


$$
\begin{aligned}
c_{t}-w_{t}= & \left(\frac{\rho_{c}}{1-\rho_{c}}\right)\left[K-\Delta w_{t+1}+\left(p_{t+1}-p_{t}\right)+\left(\frac{1-\rho_{d}}{\rho_{d}}\right)\right. \\
& \left.\left(e_{t+1}-r_{m t+1}+\rho_{b}\left(d_{t+1}-b_{t+1}\right)\right)\right]+\frac{\rho_{c}\left(1-\rho_{d}\right)}{\rho_{d}\left(1-\rho_{c}\right)}\left(b_{t}-p_{t}\right) .
\end{aligned}
$$

Equation (11) is similar to expression (10), except that we now have a contemporaneous relationship between the consumption/wealth ratio and the book/market ratio and two new variables entering inside the brackets. In particular, Eq. (11) includes the ratio of future return on equity to future market return, and the ratio of future dividend to future book/market.

If these two new ratios are approximately constant over time, given that $0<\rho_{c}<1$ and that $0<\rho_{d}<1$, a positive and contemporaneous relationship between the consumption/wealth ratio and the book/market ratio would be obtained. As expected, this does seem to be the case. We have collected both quarterly and annual data from 1991 to 2003 for the aggregate return on equity of Spanish firms ${ }^{7}$. Even though such new ratios are not constant, their variability is smaller than the other variables involved in Eq. (11), that is, the consumption/wealth ratio and the book/market ratio. Hence, we may be confident in concluding that these ratios must be sharing some common information that may be related to their trend.

Figures 1 and 2 present an empirical illustration of the relationship shown above. These figures represent the quarterly consumption/wealth ratio and the book/market ratio, in standardized units, for the US and Spanish economies, respectively. We use quarterly data from March 1963 to March 2001 for the US and quarterly data from March 1982 to December 2001 for the Spanish economy. We compute the aggregate consumption/wealth variable as the ratio between consumption and the sum of asset holdings and labor income as components of wealth. The details about each variable are provided in the next section $^{8}$. In the case of the Spanish data, the sample begins later due to the unavailability of data prior to 1982 .

It seems clear that for both economies there is a contemporaneous relationship between both ratios. They tend to be closely related to business cycles. Indeed, the correlation coefficient between both ratios turns out to be 0.86 for the Spanish case and 0.72 for the US economy.

\footnotetext{
7 This was the only variable that was unavailable in our data set. Unfortunately, we were unable to obtain the aggregate return on equity before 1991 .

8 We thank Jonathan Lewellen for providing the book/market ratio for the US market. Also, the consumption/wealth ratio is computed using the quarterly series of consumption, asset holdings, and labor income available at the homepage of Sydney Ludvigson (http://www.econ.nyu.edu/user/ ludvigsons/).
} 
Fig. 1 US btm and $c w$ ratios. This figure plots the consumption/wealth ratio (solid line) and the book/market ratio (dashed lines) for the US economy, using quarterly data form March 1963 to March 2001. Units are standardized

Fig. 2 Spanish btm and $c w$ ratios. This figure plots the consumption/wealth ratio (solid line) and the book/market ratio (dashed lines) for the Spanish economy, using quarterly data form March 1982 to December 2001. Units are standardized
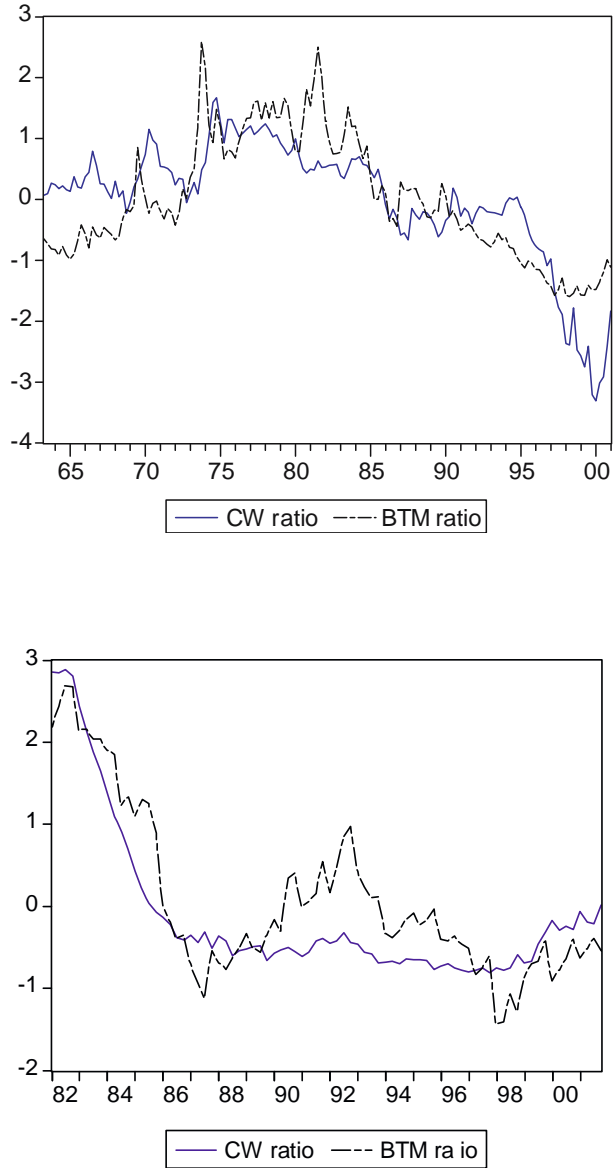

\section{The proxy for the consumption/wealth ratio}

In this section we describe the methodology employed in constructing the proxy of the consumption/wealth ratio (cay) proposed by Lettau and Ludvigson (2001a). We also discuss the data employed in computing this variable in the case of the Spanish economy. The objective is to check if a similar approximation to the consumption/wealth ratio, as in Lettau and Ludvigson, predicts returns and/or consumption growth for the Spanish market. It must be noted that, given data problems, we also propose an alternative method of computing the proxy in section "The original construction". 
A wide class of optimal models of consumer behavior implies that the log consumption/aggregate wealth ratio summarizes expected returns on aggregate wealth. Equation (9) indicates that if the consumption/wealth ratio is not constant, it must be able to predict changes in returns or consumption growth.

Because aggregate wealth contains asset holdings plus human capital, the ratio is not observable. Lettau and Ludvigson (2001a) address this problem by establishing the conditions under which the components of the ratio can be expressed in terms of observable variables - namely, $c_{t}, a_{t}$, and $y_{t}$; where $c_{t}$ is the $\log$ of consumption, $a_{t}$ is the log of nonhuman (asset) wealth, and $y_{t}$ is the log labor income. The authors demonstrate that these variables are cointegrated, and they compute a proxy for the theoretical ratio by using the cointegrating residuals. This proxy is shown to be mean-reverting and less persistent than financial ratios - convenient characteristics in cases for which the purpose is to obtain an appropriate predictor of returns. A brief description of the Lettau and Ludvigson framework is given below.

Lettau and Ludvigson impose a link between human capital and labor income by assuming that the nonstationary component of human capital, $H_{t}$, can be well described by aggregate labor income, $Y_{t}$, implying that $h_{t}=k+y_{t}+z_{t}$, where $k$ is a constant and $z_{t}$ is a mean zero stationary random variable. Thus, the log of aggregate labor income captures the nonstationary component of human capital.

Then, aggregate wealth is composed of financial wealth, which can be described by asset holdings $\left(A_{t}\right)$; plus human capital $\left(H_{t}\right)$,

$$
W_{t}=A_{t}+H_{t}
$$

and log aggregate wealth, which may be approximated as

$$
w_{t} \cong \omega a_{t}+(1-\omega) h_{t}
$$

where $\omega$ is the average share of asset holdings in total wealth $(A / W)$, which is assumed to be constant over the time ${ }^{9}$. In terms of returns, this expression implies that the return on aggregate wealth can be approximated as a weighted average of the returns to both financial and human wealth,

$$
r_{m t} \cong \omega r_{a t}+(1-\omega) r_{h t}
$$

\footnotetext{
9 We need to express the aggregate wealth in terms of the ratio $H_{t+1} / A_{t+1}$ in order to obtain $w_{t+1}=a_{t+1}+\log \left(1+\exp \left(h_{t+1}-a_{t+1}\right)\right)$. Then we take a first-order Taylor expansion around the unconditional mean of the ratio $(h-a)$.
} 
Substituting (14) into the expression for the ex-ante budget constraint (9), gives

$$
c_{t}-\omega a_{t}-(1-\omega) h_{t}=E_{t}\left[\sum_{j=1}^{\infty} \rho_{c}^{j}\left(\omega r_{a t+j}+(1-\omega) r_{h t+j}-\Delta c_{t+j}\right)\right] .
$$

Substituting the proposed formulation linking labor income to human capital into $h_{t}$, Lettau and Ludvigson obtain an expression for which we no longer have unobservable components:

$$
\begin{aligned}
c_{t}-\omega a_{t}-(1-\omega) y_{t}= & E_{t}\left[\sum_{j=1}^{\infty} \rho_{c}^{j}\left(\omega r_{a t+j}+(1-\omega) r_{h t+j}-\Delta c_{t+j}\right)\right] \\
& +(1-\omega) z_{t} .
\end{aligned}
$$

A notable feature of this equation is that all the terms on the right-hand side of (16) are presumed to be stationary. Therefore, the left-hand side must also be stationary, which in turn implies that these three variables $c, a$, and $y$ must be cointegrated. The cointegrating residual is what these authors call cay. As long as expected future returns to human capital and consumption growth are not overly volatile, or as long as these variables are highly correlated with expected returns to financial assets, it is reasonable to expect cay $y_{t}$ to be a good proxy for market expectations of future returns,

$$
\operatorname{cay}_{t}=c_{t}-\hat{\omega} a_{t}-(1-\hat{\omega}) y_{t},
$$

where "hats" denote estimated parameters.

Data

The data used in the estimation of cay are quarterly and seasonally adjusted observations. The sample period is from March 1982 to December 2003.

We have considered the final domestic consumption of households in current prices as the variable that represents aggregate consumption ${ }^{10}$. The Quarterly National Accounts published by the Spanish National Institute of Statistics provide this information.

The asset-holding data are the household and non-financial firms' net-worth series provided by the Banco de España in the Financial Accounts for the Spanish Economy. This variable is available in quarterly frequencies only from 1989.

\footnotetext{
10 Lettau and Ludvigson define consumption as real consumption of nondurables and services. However, Rudd and Whelan (2002) started debates about the consistency between the variables used by Lettau and Ludvigson and about their theoretical framework. Rudd and Whelan (2002) point out that one can formulate a consistent budget constraint using a consumption measure defined as total real consumption expenditures rather than consumption of nondurable goods.
} 
Hence, for the first 8 years, we have inferred an observable quarterly variable for the fluctuations of the annual series using the quarterly series of GDP as an indicator. The disaggregation has been made following standard state-space techniques as in Casals et al. (2004) ${ }^{11}$. The specification is based on the principle of empirical consistency, meaning that the models relating the variables in high and low sampling frequencies should be mutually compatible, given the aggregation constraint.

The third variable represents aggregate net labor income. This variable is generated with wages and salaries minus taxes at current prices. The Spanish National Institute of Statistics provides both variables. Quarterly data are available for labor salaries but not for taxes, which are available only annually. Again, we have inferred an observable quarterly indicator for fluctuations in the annual series following the same procedure as in the case of asset holdings.

All series are deflated by the consumer price index $(1995=100)$, provided by the Spanish National Institute of Statistics.

The first problem we need to address is that, unlike the US data, Spanish net asset holdings data $\left(A_{t}\right)$ do not always have a positive sign. The series is expressed in net terms (financial assets less financial liabilities) and an important part of the household investments, namely real assets, is not taken into account. Unfortunately, there is no information available for real estate wealth in Spain prior to 1987. Moreover, the net asset holding series data that are available include non-financial firms, and a disaggregated series between households and firms is not provided until 1989. Indeed, our series is negative from March 1982 to the second quarter of 1983. Because the approximation proposed by Lettau and Ludvigson (2001a) takes logarithms, we cannot use it for these negative values. We address this problem with two solutions. First, we assign a value of one to those seven quarters where we have a negative value, so the log will be zero. Then, total wealth is computed by subtracting the value of net asset holdings from salaries. In this way, the overall amount of both variables that approximate total wealth of the period will be the same. A second alternative for these seven quarters is to work with only one variable adding asset holdings and labor income $(W=A+Y)$ directly. In this case, we denote the variable as $c w$.

Next, we use the procedure suggested by Johansen $(1988,1991)$ to infer the number of cointegrating vectors between consumption and the different components of wealth, if they exist; and to estimate the parameters of these vectors. The procedure sets a $p$-dimensional vector autoregressive model (VAR) with $k$ lags, where $p$ is the number of variables for which we study cointegration. In our case, $p$ is either 3 (for cay) or 2 (for $c w$ ). Under the null hypothesis that there are exactly $r$ cointegrating relations, the Trace statistic generates a likelihood ratio test of the null hypothesis against the alternative that there are $p$ cointegrating

\footnotetext{
11 The procedures used are implemented in a Matlab toolbox for time series modeling called E4, which can be downloaded at http://www.ucm.es/info/icae/e4. The source code for all the functions in the toolbox is freely provided under the terms of the General Public License.
} 
Table 1 Johansen cointegration test

\begin{tabular}{|c|c|c|c|c|c|}
\hline \multicolumn{3}{|c|}{ Variables $c_{t}, a_{t}$, and $y_{t}$} & \multicolumn{3}{|c|}{ Variables $c_{t}$ and $w_{t}$} \\
\hline$H_{0}=r$ & Trace & $5 \% \mathrm{CV}$ & $H_{0}=r$ & Trace & $5 \% \mathrm{CV}$ \\
\hline \multicolumn{6}{|c|}{ One lag in VAR model } \\
\hline 0 & $29.72^{\mathrm{a}}$ & 29.68 & 0 & 11.14 & 15.41 \\
\hline 1 & 7.20 & 15.41 & 1 & 0.088 & 3.76 \\
\hline 2 & 1.83 & 3.76 & & & \\
\hline \multicolumn{6}{|c|}{ Three lags in VAR model } \\
\hline 0 & $31.16^{\mathrm{a}}$ & 29.68 & 0 & $20.28^{\mathrm{a}}$ & 15.41 \\
\hline 1 & 7.23 & 15.41 & 1 & 1.31 & 3.76 \\
\hline 2 & 0.57 & 3.76 & & & \\
\hline
\end{tabular}

This table reports the statistics for the cointegration Johansen test. The Trace statistic offers a test for the hypothesis of $r$ cointegrating relations. The test depends on the number of lags assumed in the VAR model.

a The rejection of the null hypotheses at a $5 \%$ level of significance

relations. The test depends on the number of lags assumed in the VAR model. Table 1 reports the results under one and three lags.

The critical values obtained using this approach depend on the trend characteristics of the data. We report our results allowing for linear trends, but assuming that the cointegrating relationship has only a constant. When we use consumption, labor income, and asset holdings, the null hypothesis of zero cointegrating relationship is rejected against one relationship. If we consider only consumption and aggregate wealth, the same result is obtained for the three-lags case.

The estimated parameters for the two cointegrating relationships among consumption, asset holdings, and labor income are given by

$$
\text { cay }_{t}=c_{t}-2.414-0.0042 a_{t}-0.817^{*} y_{t} \quad \text { and } \quad c w_{t}=c_{t}-4.708-0.553^{*} w_{t} .
$$

The asterisk indicates that the estimate is statistically significant. The inference of these parameters is based on a likelihood ratio test imposing the restriction that each parameter is equal to zero on the cointegrating vector. Despite the significance of the coefficient that relates consumption and wealth in the second cointegrating relationship, unfortunately, we cannot reject the hypothesis of the existence of unit roots in $c w$. Thus, for our predicting exercise, we only use the standard cay.

Forecasting returns and consumption growth

In this section, we investigate the power of the Spanish proxy of the consumption/wealth ratio constructed above in forecasting consumption growth rates and returns at different horizons. Following Eq. (9), an increase in the consumption/wealth ratio must precede a higher future market return or a smaller future consumption growth. Before presenting the results of the forecasting 
regressions, we describe the financial data used to compute market returns and any other financial variables used in the subsequent sections of the paper.

\section{Financial data}

Data are quarterly from March 1982 to December 2003. The sample includes 205 stocks that have been quoted at some time in our sample period. For each individual asset we compute three variables: the rate of return, the book/market ratio, and the dividend yield. The quarterly asset return is obtained as the ratio of the price of the stock at the end of the current quarter to the price at the end of the previous quarter. We add all dividends paid during this period and adjust the returns for splits and seasoned equity issues. To compute the book/market ratio in a quarter, we use the book value of each stock at December 30 of the previous year and the product of the number of shares and the price of the stock at the end of the corresponding quarter. Book/market is calculated as the ratio of these two values. The dividend yield is obtained as the ratio of the sum of all dividends paid by the company in the last four quarters to the price at the end of the last quarter.

We compute the corresponding aggregate data from the individual data. The market return is approximated by two indexes: An equally-weighted index calculated as the average of all stock returns available at a given quarter and a value-weighted index, using the market value of each asset at the end of December of the previous year. Both index returns are computed in excess of a risk-free rate to have real rates of returns. We denote by ree and rve the excess returns on the equally weighted and value-weighted indices respectively. The quarterly implicit return of the one-year Treasury bonds is used as a risk-free rate up to December 1987 and the quarterly one-year Treasury bill rate after this date. The aggregate book/market ratio (btm) and the aggregate dividend yield $(d y)$ are obtained as the simple average of the individual ratios. Finally, we use a variable that represents the term spread of interest rates $(d t i)$ computed as the difference between the quarterly 10-year Treasury bond yield and the risk-free rate. All these variables are expressed in logs.

\section{Empirical evidence}

Panel A of Table 2 reports the summary statistics for the two market return indexes, aggregate consumption growth rate, and the proxy of the consumption/wealth ratio. We observe that the equally weighted market excess returns present a higher average return and higher volatility than does the valueweighted index. This reflects the well known size effect during the sampling period. The variable cay has a negative mean, and it is more volatile than is the proxy computed by Lettau and Ludvigson (2001a) for US data. This is a desirable characteristic when the objective of the proxy is to forecast returns. However, in the case of Spain, this proxy is highly persistent. In particular, the serial correlation is 0.89 , which implies that caution must be exercised when drawing 
inferences about the forecasting ability of this variable. The autocorrelation of cay using US data is lower at 0.79 .

Panel B of Table 2 reports the results of regressing excess returns or consumption growth on one-period-lagged cay at different horizons. We compute cumulative excess returns from 1 to 8 quarters as the sum of $H$ $(H=1,2, \ldots, 8)$ excess returns on both market indices $\left(\right.$ ree $_{H}=$ ree $_{t}+\cdots+$ ree $_{t+h}$ and $\left.r v e_{H}=r v e_{t}+\cdots+r v e_{t+h}, h=1, \ldots, 7\right)$ and use this as the dependent variable. Similarly, the cumulative log consumption growth rate is computed as $\Delta c_{H}=\Delta c_{t}+\cdots+\Delta c_{t+h}, h=1, \ldots, 7$. For each regression, Table 2 reports the point estimates of the explanatory variable and its $t$-statistic either in parenthesis or in brackets. The statistical properties of residuals in the predicting regressions were analyzed by the Breusch (1978) test for serial correlation and the White (1980) test for heteroskedasticity. In general we find serial correlation whenever we employ a cumulative dependent variable in the regressions. In these cases, standard errors are adjusted by the Newey-West procedure and the corresponding $t$-statistic is given in parenthesis. Otherwise, the $t$-statistics are based on the OLS standard errors, which are provided in brackets. No evidence of heteroskedasticity was found.

The results indicate that the forecasting ability of cay is negligible, at least in the sense that theory predicts. Surprisingly, cay is a statistically significant predictor of equally weighted returns for horizons of three-quarters and longer, but with the opposite sign to that expected from Eq. (9). Using the value-weighted index, cay is not statistically significant. Therefore, economically speaking, the success of our proxy of the consumption/wealth ratio for Spanish data in predicting returns seems to be highly problematic. This is in contrast with evidence

Table 2 Forecasting with long-horizon regressions using cay

\begin{tabular}{|c|c|c|c|c|c|}
\hline & ree & rve & $\Delta c$ & cay & \\
\hline \multicolumn{6}{|c|}{ Panel A: summary statistics } \\
\hline Mean & 2.573 & 1.788 & 0.718 & -0.306 & \\
\hline SD & 14.52 & 12.95 & 1.731 & 4.381 & \\
\hline Autocorr. & 0.024 & -0.098 & -0.504 & 0.834 & \\
\hline $\mathrm{H}$ & 1 & 2 & 3 & 4 & 8 \\
\hline \multicolumn{6}{|c|}{ Panel B: long-horizon regressions } \\
\hline ree & $\begin{array}{l}-0.143 \\
{[-0.421]}\end{array}$ & $\begin{array}{l}-0.459 \\
(-1.103)\end{array}$ & $\begin{array}{l}-0.977 \\
(-2.097)\end{array}$ & $\begin{array}{l}-1.582 \\
(-2.980)\end{array}$ & $\begin{array}{l}-2.951 \\
(-3.391)\end{array}$ \\
\hline rve & $\begin{array}{l}0.018 \\
{[0.060]}\end{array}$ & $\begin{array}{l}-0.123 \\
(-0.329)\end{array}$ & $\begin{array}{l}-0.425 \\
(-0.945)\end{array}$ & $\begin{array}{l}-0.809 \\
(-1.432)\end{array}$ & $\begin{array}{l}-1.774 \\
(-1.927)\end{array}$ \\
\hline$\Delta c$ & $\begin{array}{l}-0.017 \\
(-0.348)\end{array}$ & $\begin{array}{l}0.039 \\
(0.931)\end{array}$ & $\begin{array}{l}0.065 \\
(1.199)\end{array}$ & $\begin{array}{l}0.171 \\
(3.245)\end{array}$ & $\begin{array}{l}0.319 \\
(4.537)\end{array}$ \\
\hline
\end{tabular}

Panel A: Summary statistics of all variables are reported. Ree is the quarterly log excess return on a equally weighted index of all stocks in the sample; rve is the log excess return on a value-weighted index; $\Delta c$ is the real consumption growth rate; and cay represents the cointegrating residual of consumption, asset holdings, and labor income $\left(c_{t}-2.414-0.0042 a_{t}-0.817 y_{t}\right)$

Panel B: OLS estimates of the forecasting regressions of the $H$-period excess returns (ree or rve) or consumption growth on one-period lagged cay. OLS $t$-statistics are in brackets and the $t$-statistics based on Newey and West (1987) standard errors are in parenthesis. The sample period is 1982:1 to $2003: 4$ 
obtained for the US data, in which a positive and statistically significant forecasting ability of future excess returns is found at short- and long-term horizons.

Independent of the ability of cay to forecast future returns, it should forecast changes in consumption growth. The last row of Table 2 reports the results of these forecasting regressions. Once again, the signs of the estimates are theoretically incorrect, except for the slope of cay in the one-quarter horizon regression, when the result is not statistically different from zero.

\section{A new approach to estimate the consumption/wealth ratio}

The components of wealth

The surprisingly poor results obtained with the consumption/wealth ratio proxy proposed by Lettau and Ludvigson (2001a) using Spanish data suggest that various problems confronted when measuring aggregate wealth may explain the lack of correct predictability. First, as we mentioned in the data description, asset holdings represent joint net financial assets of households and non-financial firms. It is impossible to distinguish which part corresponds to households until the fourth quarter of 1989. Second, with the empirical decomposition of aggregate wealth proposed by the authors, we are failing to account for an important part of the investments of families in Spain - namely real estate holdings. Unfortunately, information on aggregate real estate wealth is available only since the second quarter of 1987 . Third, the non-financial component of wealth is human capital. Because human capital is not observable, the usual practice is to link labor income to the stock of human capital (Campbell 1996; Jagannathan and Wang 1996; Lettau and Ludvigson 2001a). But labor income is a bad proxy for human capital when the return on human capital changes over time if the characteristics of the working population change during the sample period. It may be of great interest to use alternative measures of human capital based on these time-varying characteristics, and check the robustness of previous results.

The objective of this section is to improve the measure of aggregate wealth along the lines described above. However, improving the proxy of the consumption/wealth ratio in that sense forces us to reduce the sample period from 1989:4 to 2003:4, because of the availability of data in Spain.

\section{Additional data}

The quarterly series for real estate wealth and financial net asset household holdings from 1989:4 to 2003:4 are from the Financial Accounts of the Spanish Economy reported by the Banco de España.

As indicated above, measuring human wealth with aggregate labor income is questionable in the sense that salaries do not appropriately represent the working value of the population. In this way, literature of economic growth approximates the value of human capital, explicitly accounting for certain characteristics of the population such as age or the level of education for each 
individual. In the specific case of Spain, we follow Serrano and Pastor (2002) in constructing a measure consistent with these ideas. Next, we describe the key points behind the construction of this proxy. A more detailed explanation of the methodology and the data used can be found in Appendix A.

First, the human capital value of an individual at a specific time is computed as the present value of all that person's future salaries until retirement age. Second, salary is allowed to depend on the age, sex, and level of education of each individual. Finally, a proxy of aggregate human capital at each time $t$ is the sum of the present value of the salaries of all individuals.

In this case, the cointegration relationship implies four variables, $c_{t}, a_{t}, r_{t}$ and $h_{t}$, where $c_{t}$ is the log of real consumption, $a_{t}$ the log of net financial assets holdings, $r_{t}$ the log of real estate wealth, and $h_{t}$ the log of our measure of human capital. The cointegration residuals using these four components are called carh. In particular, the equation generated for carh with the normalized coefficients of cointegration is given by

$$
c_{t}-6.903-0.463 a_{t}-0.623 r_{t}+0.668 h_{t} .
$$

As before, we verify the statistical significance of all the coefficients in the previous estimated relationship using a likelihood ratio test and the stationarity of our proxy by a unit root test.

Forecasting returns and consumption growth

Table 3 shows the results when the carh variable is used. The first panel reports summary statistics for the variables employed in this shorter sample period. The mean and volatility of carh are lower than in the standard cay. However, the most important finding here is that the new proxy for the consumption/wealth ratio has a much lower serial correlation. In particular, the autocorrelation coefficient is equal to 0.3 , which contrasts with the high persistence found in the proxy for the standard cay.

Panel B of Table 3 presents the slopes of single-equation regressions of excess return on equally weighted index, excess return on value-weighted index, or consumption growth rate over horizons spanning 1 to 8 quarters. The table reports the coefficient of the one-period lagged carh and the $t$-statistic for individual significance tests. The OLS $t$-statistics are in brackets, whereas the $t$-statistics based on the Newey-West standard errors are in parenthesis.

The results show that carh is able to forecast the equally weighted market excess returns only at 2- and 3-quarter horizons. More importantly, the capability of forecasting the value-weighted index is presented at 1-, 2-, 3-, and 4-quarter horizons. Moreover, for both market indexes, the prediction is with the right sign according to Eq. (9). Finally, the prediction of consumption growth is promising, though weaker than in the case of returns. It should be recalled that consumption growth has proven difficult to forecast ${ }^{12}$. Increases in carh suggest

12 See Cochrane (2001) for an excellent review of this evidence. 
Table 3 Forecasting with long-horizon regressions using carh

\begin{tabular}{|c|c|c|c|c|c|}
\hline & & ree & rve & $\Delta c$ & carh \\
\hline \multicolumn{6}{|c|}{ Panel A: summary statistics } \\
\hline Mean & & 0.465 & 0.815 & 0.711 & -0.027 \\
\hline $\mathrm{SD}$ & & 13.51 & 12.92 & 0.970 & 2.780 \\
\hline Autocorr. & & -0.027 & -0.159 & -0.136 & 0.305 \\
\hline $\mathrm{H}$ & 1 & 2 & 3 & 4 & 8 \\
\hline \multicolumn{6}{|c|}{ Panel B: long-horizon regressions } \\
\hline ree & $\begin{array}{l}0.850 \\
{[1.228]}\end{array}$ & $\begin{array}{l}2.098 \\
(2.889)\end{array}$ & $\begin{array}{l}3.063 \\
(2.757)\end{array}$ & $\begin{array}{l}2.375 \\
(3.146)\end{array}$ & $\begin{array}{l}2.237 \\
(0.906)\end{array}$ \\
\hline rve & $\begin{array}{l}1.244 \\
{[1.918]}\end{array}$ & $\begin{array}{l}1.935 \\
(3.171)\end{array}$ & $\begin{array}{l}2.583 \\
(2.808)\end{array}$ & $\begin{array}{l}2.717 \\
(2.490)\end{array}$ & $\begin{array}{l}1.283 \\
(0.793)\end{array}$ \\
\hline$\Delta c$ & $\begin{array}{l}-0.113 \\
{[-2.350]}\end{array}$ & $\begin{array}{l}-0.148 \\
(-1.632)\end{array}$ & $\begin{array}{l}-0.207 \\
(-2.031)\end{array}$ & $\begin{array}{l}-0.127 \\
(-1.004)\end{array}$ & $\begin{array}{l}0.034 \\
(0.127)\end{array}$ \\
\hline
\end{tabular}

Panel A: Summary statistics of all variables are reported. Ree is the quarterly log excess return on a equally-weighted index of all stocks in the sample; rve is the log excess return on a value-weighted index; $\Delta c$ is the real consumption growth rate; and carh represents the cointegrating residual of consumption, asset holdings, real estate, and human capital $\left(c_{t}-6.903-0.463 a_{t}-0.623 r_{t}+0.668 h_{t}\right)$ Panel B: OLS estimates of the forecasting regressions of the $H$-period excess returns (ree or rve) or consumption growth on one-period lagged cay. OLS $t$-statistics are in brackets and the $t$-statistics based on Newey and West (1987) standard errors are in parenthesis. The sample period is 1989:4 to 2003:4

falls in the consumption growth rate for 1, 2 and 3 future quarters. Again, the sign is consistent with the theory. These are striking results that point out the importance of using specific-country characteristics when developing a proxy for the consumption/wealth ratio.

To get a visual impression of the behavior of our proxy for the consumption/wealth ratio, Fig. 3 plots the standardized carh and the standardized excess return on the value-weighted index over the period from 1989:4 to 2003:4. First, the dashed line that plots carh indicates that this variable shows mean reversion and is sufficiently volatile to be able to anticipate changes in returns. Second, comparing the movements in carh and rve, we can observe the tight link between these two variables. There are several relevant episodes of the cycle during which increases and decreases of carh precede positive and negative spikes in excess returns, respectively.

\section{Robustness}

The results in the previous section indicate that both the actual definition and the measurement of the components of aggregate wealth are key aspects if we want to compute a good proxy of the consumption/wealth ratio, at least for the case of Spain. However, due to the shortness of the sample period (from 1989:4 to 2003:4), a new problem arises. The results could be biased in favor of the less persistent variable, carh, as opposed to cay. To shed light on this question, we address the problem of the sample size by constructing a sensibly better 
Fig. 3 Excess return on the value-weighted index and carh. The figure plots the excess return on the value-weighted index (solid line) and the proxy of the consumption/wealth ratio, namely carh (dashed line), using quarterly data from December 1989 to December 2003. Units are standardized

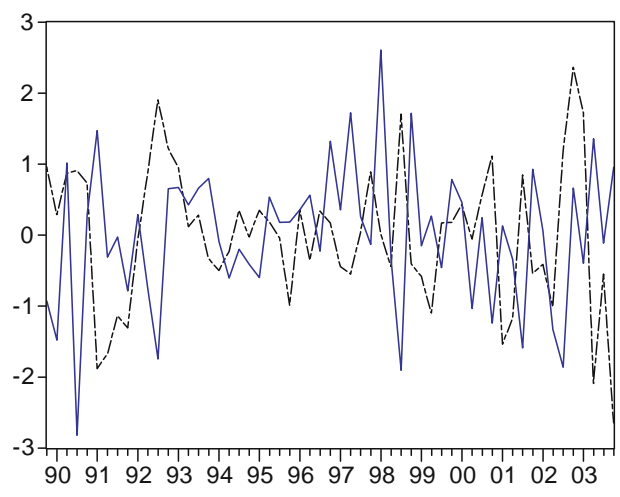

--- carh - rve

proxy over a longer period than that employed in section "The proxy for the consumption/wealth ratio".

\section{A Longer series for the consumption/wealth ratio}

To extend the sample period, we first compute two proxies of the consumption/wealth ratio for two subsamples with the information available in each of the corresponding periods. We then connect the two series. For the first subsample, between 1982:1 and 1989:3, we compute the proxy following the methodology described in section "The proxy for the consumption/wealth ratio". That is, we estimate the cointegrating relationship among aggregate consumption, asset holdings, and labor income. The variable is again cay, because it is computed as in Lettau and Ludvigson (2001a) work. However, the values at each time are not the same as those obtained in Section "The proxy for the consumption/wealth ratio" because the sample period is shorter and the parameters of the cointegrating relationship are different. As before, we are of course aware of the problems contained in these data during this period, but this is our only possibility of implementing the proxy. For the second subsample, from 1989:4 to $2003: 4$, we use the values of carh. We denote the final variable as cay-carh.

Empirical evidence with a longer series: the consumption/wealth ratio versus financial predictors

As expected, the results with the longer series are not as impressive as those in Table 3. However, Table 4 shows that cay-carh retains the forecasting power on the excess return of the value-weighted index at 1-, 2-, and 3-quarter horizons. Moreover, the signs are as expected, given the theoretical expression. Figure 4 illustrates this finding. 
Table 4 Forecasting with long-horizon regressions using the longer proxy cay-carh

\begin{tabular}{llllll}
\hline $\mathrm{H}$ & 1 & 2 & 3 & 4 & 8 \\
\hline ree & 0.646 & 1.358 & 1.601 & 1.755 & 1.677 \\
& {$[1.580]$} & $(2.663)$ & $(1.885)$ & $(1.605)$ & $(0.851)$ \\
rve & 0.726 & 1.126 & 1.264 & 1.351 & 1.077 \\
& {$[2.007]$} & $(2.821)$ & $(1.970)$ & $(1.782)$ & $(0.794)$ \\
$\Delta c$ & -0.107 & -0.100 & -0.143 & 0.029 & 0.029 \\
& $(-1.543)$ & $(-1.475)$ & $(-1.794)$ & $(0.326)$ & $(0.199)$ \\
\hline
\end{tabular}

The table reports OLS estimates of the forecasting regressions of the $H$-period excess returns (ree or $r v e$ ) or consumption growth on one-period lagged cay-carh. Ree is the quarterly log excess return on a equally-weighted index of all stocks in the sample; rve is the log excess return on a value-weighted index; $\Delta c$ is the real consumption growth rate; and cay-carh represents the cointegrating residual of consumption, asset holdings, and labor income from 1982:1 to 1989:3 and the cointegrating residuals of consumption, asset holdings, real estate and human capital from 1989:4 to 2003:4. OLS $t$-statistics are in brackets and the $t$-statistics based on Newey and West (1987) standard errors are in parenthesis

Fig. 4 Excess return on the value-weighted index and cay-carh. The figure plots the excess return on the value-weighted index (solid line) and the proxy of the consumption/wealth ratio, namely cay-carh (dashed line), using quarterly data from March 1982 to December 2003. Units are standardized

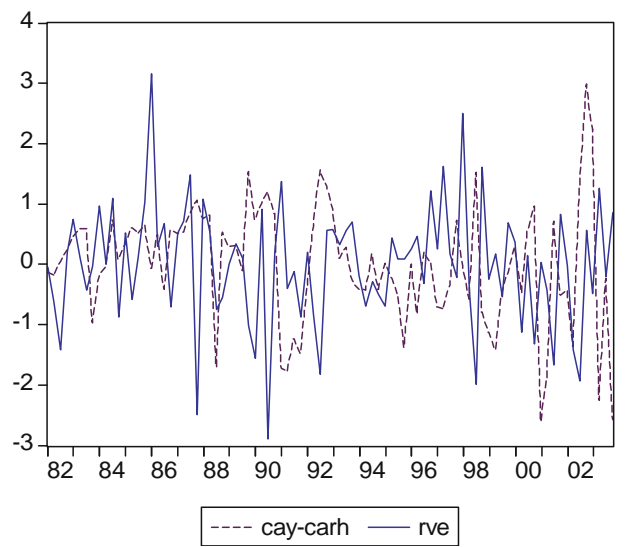

To check for robustness, we also analyze the predicting ability of cay-carh, using forecasting regressions that include other variables shown elsewhere to contain predicting power for returns: the book/market ratio $(\mathrm{btm})$, the dividend yield $(d y)$, and the term spread $(d t i) .{ }^{13}$ Table 5 presents summary statistics for these variables.

The new proxy of the consumption/wealth ratio has a mean and standard deviation similar to those of the other proxies, but is much less persistent than the Lettau and Ludvigson proxy. Its autocorrelation of 0.3 is in line with that obtained for the shorter cahr. On the other hand, it is not strongly

13 Nieto (2002) has analyzed the forecasting power of these variables for the Spanish market in a similar sample period, but with monthly data. She finds that $\mathrm{btm}$ is a good predictor of returns. 
Table 5 Summary statistics

\begin{tabular}{lllll}
\hline & cay-carh & btm & $d y$ & $d t i$ \\
\hline Mean & -1.190 & 12.718 & 3.674 & 0.406 \\
SD & 3.929 & 66.923 & 2.023 & 0.509 \\
Autocorr. & 0.299 & 0.962 & 0.939 & 0.876 \\
Correlation matrix & & & & \\
cay-carh & 1 & 0.133 & 0.100 & 0.017 \\
btm & & 1 & 0.936 & 0.504 \\
dy & & & 1 & 0.557 \\
$d t i$ & & & & 1
\end{tabular}

The table shows the summary statistics of financial variables and the proxy for the consumption/wealth ratio. Cay-carh is the cointegrating residuals of consumption, asset holdings, and labor income from 1982:1 to 1989:3 and the cointegrating residuals of consumption, asset holdings, real estate, and human capital from 1989:4 to 2003:4. Btm is the aggregate book/market ratio and $d y$ is the aggregate dividend yield. They are computed as the simple average of the corresponding individual measures for all stocks in the sample. Dti is the yield spread between long- and short-term interest rates. The sample period is 1982:1 to 2003:4

contemporaneously correlated with the other variables. As usual, the rest of variables are persistent, and btm and $d y$ are also highly correlated.

Tables 6 and 7 report the results from one-quarter-ahead forecast regression using excess returns on the equally weighted and value-weighted market indexes respectively. Each row contains two results. First, given that the residuals of the regressions do not show either heterokedasticity or serial autocorrelation, the OLS $t$-statistic is used. Second, because of the persistence and highly correlated regressors, we report below the bias-corrected estimator and the bias-corrected $t$-statistic proposed by Amihud and Hurvich (2004). These authors suggest an augmented regression method (ARM) for hypothesis testing in predictive regressions with multiple autoregressive predictor variables. Their simulations show that their adjustment outperforms other bias-correction methods such as those suggested by Stambaugh (1999) or Lewellen (2004). Both $t$-statistics are in parenthesis. Moreover, given the correlation between the explanatory variables, and besides the adjusted $R^{2}$, an $F$-statistic for the joint significance of all coefficients is reported in the last column of this table.

In Table 6, focusing on the individual forecasting regressions and on the first two results of each row, we can see that cay-carh, btm, and $d y$ have limited power in forecasting the excess return of the equally weighted index. The coefficients are positive according to theory: An increase in aggregate dividend yield or an increase in the aggregated book value of the firms with respect to their market value produces an increase in the next quarter's stock market prices. In the case of cay-carh, if investors expect a decline in future returns and want to smooth consumption, they will temporarily reduce consumption below their long-term proportion of consumed wealth. The adjusted $R^{2}$ of these three regressions are similar and small (over $1.5 \%$ ), but considerably larger than the $R^{2}$ of regressions of the excess returns on the term spread, which has no forecasting power. Combining btm or $d y$ with cay-carh in multiple predictive regressions, the results 
Table 6 Forecasting regressions of the excess return on equally-weighted index

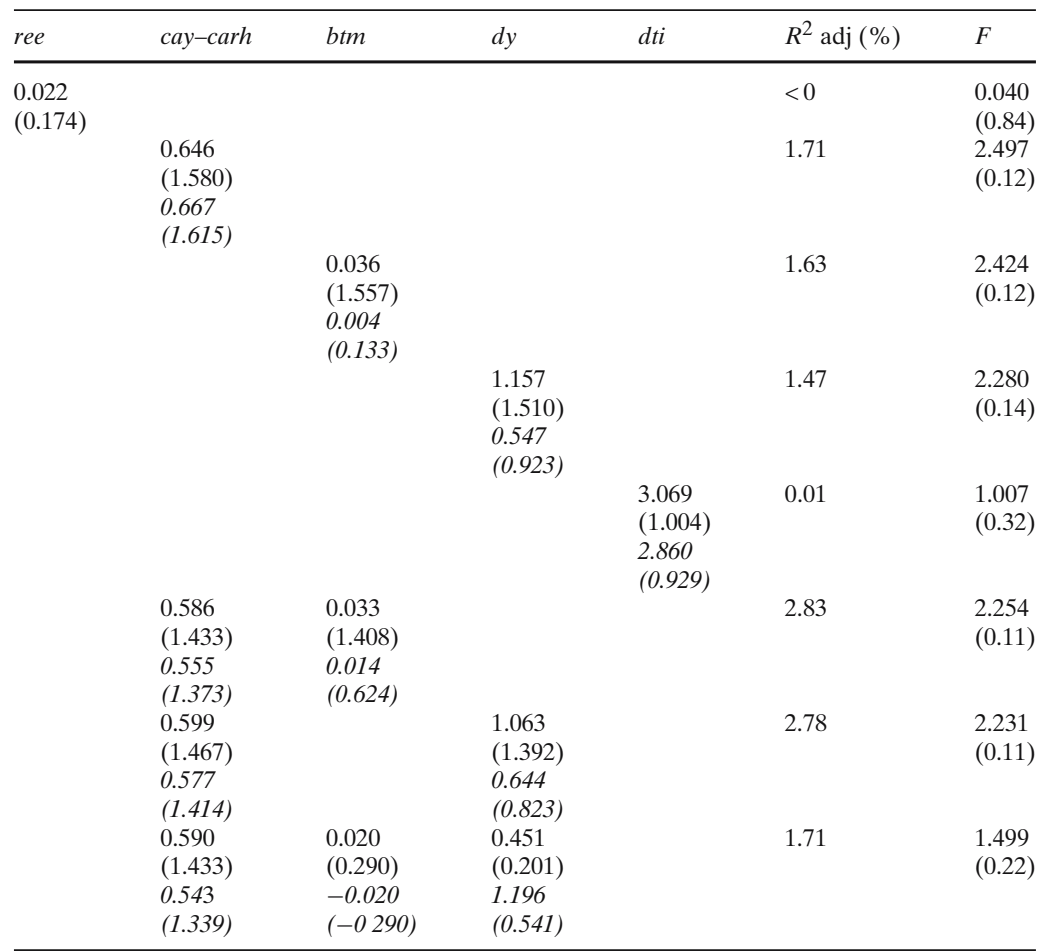

The table reports OLS estimates of the forecasting regressions of the equally weighted market excess return on one-period lagged variables in the first row. Ree is the quarterly log excess return on a equally weighted index of all stocks in the sample. Cay-carh represents the cointegrating residual of consumption, asset holdings, and labor income from 1982:1 to 1989:3 and the cointegrating residuals of consumption, asset holdings, real estate, and human capital from 1989:4 to 2003:4. Btm is the aggregate book/market ratio and $d y$ is the aggregate dividend yield. They are computed as the simple average of the corresponding individual measures for all stocks in the sample. Dti is the yield spread between long- and short-term interest rates. OLS $t$-statistics are in parenthesis. The last two figures in each row written with cursive characters are the adjusted estimates and $t$-statistics proposed by Amihud and Hurvich (2004). The last two columns show the adjusted $R^{2}$ in percentage terms and the $F$-statistic for joint significance of the coefficients. The sample period is $1982: 1$ to $2003: 4$

of each variable are similar to those obtained in the individual cases, but the adjusted $R^{2}$ increase to $2.8 \%$. However, when all three variables are included in the regression, the weak predictability found in btm and $d y$ completely disappears and the $R^{2}$ decreases to the level obtained with cay-carh alone. The $F$-test is unable to reject the null hypothesis that all regressor coefficients are jointly zero. 
Table 7 Forecasting regressions of the excess return on value-weighted index

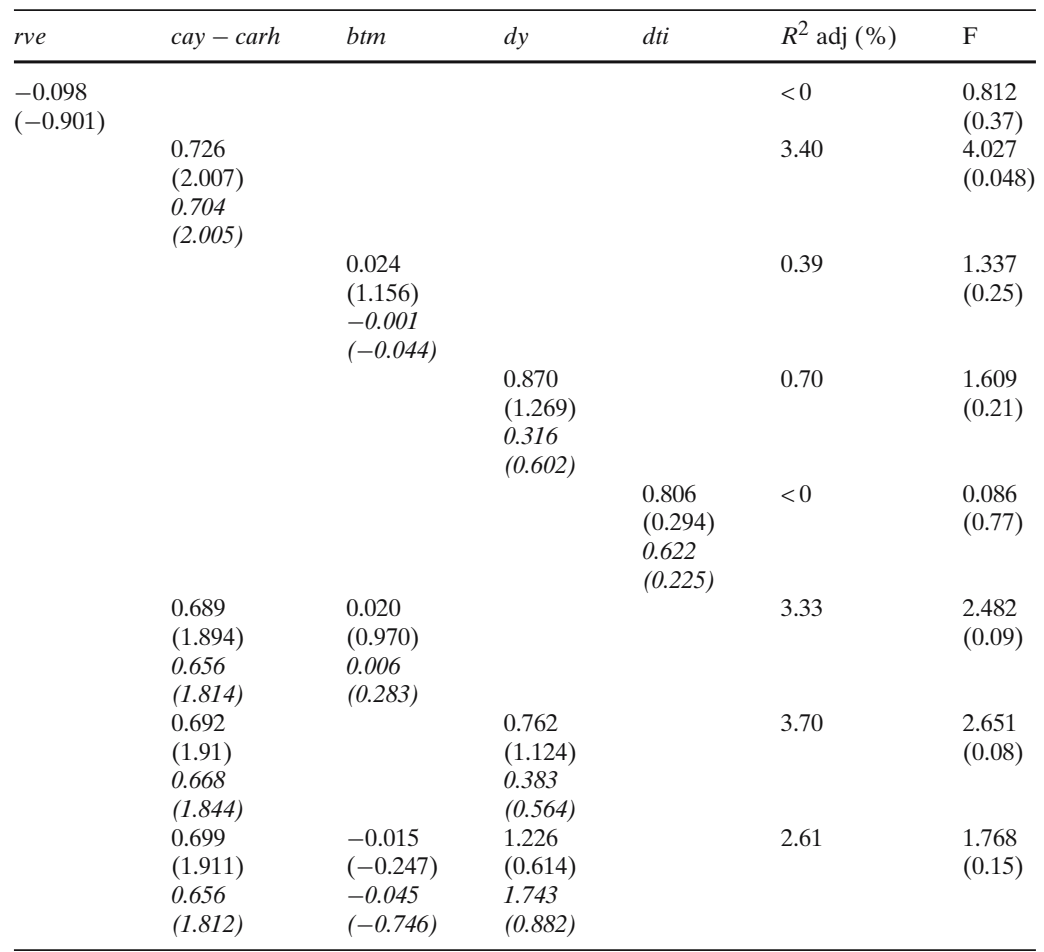

The table reports OLS estimates of the forecasting regressions of the value-weighted market excess return on one-period lagged variables in the first row. Rve is the quarterly log excess return on a value-weighted index of all stocks in the sample. Cay-carh represents the cointegrating residual of consumption, asset holdings, and labor income from 1982:1 to 1989:3 as well as the cointegrating residuals of consumption, asset holdings, real estate, and human capital from 1989:4 to 2003:4. Btm is the aggregate book/market ratio and $d y$ is the aggregate dividend yield. They are computed as the simple average of the corresponding individual measures for all stocks in the sample. Dt is the yield spread between long- and short-term interest rates. OLS $t$-statistics are in parenthesis. The last two figures in each row written with cursive characters are the adjusted estimates and $t$-statistics proposed by Amihud and Hurvich (2004). The last two columns show the adjusted $R^{2}$ in percentage terms, and the $F$-statistic for joint significance of the coefficients. The sample period is 1982:1 to 2003:4

When the estimates and $t$-statistics are adjusted by the bias correction of Amihud and Hurvich (2004), the results from individual regressions indicate that, at the $10 \%$ level of significance, only cay-carh has a positive effect on excess returns at the one-quarter horizon. In the case of $d y$ and btm, the loss in significance is due to the high autocorrelation of these variables, consistent with the results reported for $d y$ in Amihud and Hurvich (2004). The evidence from multiple regressions confirms the individual regressions results. 
Table 7, in which value-weighted index is used, confirms the findings shown in Tables 4 and 6 . Using both OLS and bias-corrected $t$-statistics, the predictive capacity of cay-carh on future returns is even clearer than before. As with Lettau and Ludvigson (2001a), the proxy for the consumption/wealth ratio is better at forecasting the value-weighted market index. This fact is not surprising if we recall the well known size, value, and illiquidity effects. In the value-weighted index, the small and more illiquid assets receive relatively lower weights than in the equally weighted index. This implies that the error measurement introduced in the aggregate market return is smaller. Hence, it seems reasonable to expect that macroeconomic data associated with the business cycle has more forecasting power for the value-weighted index than for the equally weighted market return.

The one-period lagged regression of excess returns on cay-carh generates an adjusted $R^{2}$ statistic of $3.4 \%$, and the $F$-statistic rejects the null hypothesis that all coefficients are jointly zero.

Finally, the results with the other variables are consistent with those shown in Table 6. The parameters are estimated with little precision and the OLS $t$ statistics are too small to indicate that the estimates are statistically significant. Moreover, as expected, estimates and $t$-statistics under the Amihud and Hurvich (2004) adjustment are smaller. Along this line, although the $R^{2}$ increases to $3.7 \%$ when combining $d y$ with cay-carh, the $F$-statistics do not justify rejection of the null hypothesis that all coefficients are jointly zero at a $5 \%$ level of significance.

\section{Conclusion}

Given the budget constraint of intertemporal portfolio decision problems, there must be a positive relationship between future market returns and the proportion of wealth consumed at a given moment in time. In fact, the empirical success for the proxy of the consumption/wealth ratio proposed by Lettau and Ludvigson (2001a) is impressive. Simultaneously, empirical literature has shown the power of financial ratios such as the book/market and dividend yield in explaining future changes in returns. This article argues that these empirical findings about predictability found for the log consumption/wealth and the $\log$ book/market ratios should not be understood as independent phenomena. In particular, we develop an expression similar to the equation based on the intertemporal budget constraint, which is based on a well known accounting principle that shows the theoretical ability of the book/market ratio to predict returns. Moreover, we provide a theoretical expression suggesting that book/market and consumption/wealth ratios must be positive and contemporaneously related. Along this line, we report a high contemporaneous correlation between these two ratios in both the United States and Spain.

Lettau and Ludvigson (2001a) compute a proxy for the fluctuations in the consumption/aggregate wealth ratio, in which consumption, asset holdings, and labor income are cointegrated. Then they show that the cointegrating residuals forecasts returns. The computation and empirical evidence of this variable for 
the Spanish market clearly indicates the importance of adequately measuring the components of wealth. In particular, when we account for age, level of education, and sex when measuring human capital, and if we simultaneously incorporate real estate holdings as an important part of household wealth in Spain, we find that our proxy is able to forecast excess returns at short- and long-term horizons. This finding strongly contrasts with the behavior in Spain of the standard proxy proposed by the authors. Moreover, as expected, this is especially true when the value-weighted index is used. This is an important finding, which suggests that the idiosyncratic characteristics of each country should be carefully accounted for when using cay to predict returns.

Our proxy is relatively volatile and mean-reverting, which are desirable properties for a predictor of returns. Moreover it has lower persistence levels than does the standard proxy of the consumption/wealth ratio and, of course, less than the typical financial ratios such as dividend yield or book/market. Thus, our new proposal maintains its forecasting power in a multiple regression context even after the Amihud and Hurvich (2004) bias adjustment is taken into account. This is not the case for alternative traditional financial predictors such as book/market or dividend yield ratios.

To conclude, our results show that cay is alive and well. However, it becomes crucial to measure its components correctly. The mechanical adaptation of cay to European countries seems to be problematic, to say the least. This may be especially important when testing conditional asset pricing models with European data.

Acknowledgements The authors are grateful to Jose Manuel Campa, Amaia Iza, Miguel Jerez, Fernando Restoy, Sara de la Rica, Antonio Villar, and three anonymous referees for useful comments, suggestions, and assistance that substantially improved previous versions of the paper. We are especially indebted to Gonzalo Rubio for his comments, advice, and support. We would also like to thank the anonymous referee at IVIE, which published a preliminary version in its working paper series, WP-EC-2002-24. Any remaining errors are our own.

\section{Appendix A: Measuring the human capital}

In order to implement the methodology proposed by Serrano and Pastor (2002) for computing the value of human capital, we classify the working population into groups according to three categories that are important characteristics for the value assigned to an individual by the job market: sex, age, and level of education. Each category is divided into various groups: two groups for sex (males and females); eleven groups for age, covering people who are between 16 and 69-years-old; and seven groups for level of education, ranging from no formal education to advanced graduate studies. ${ }^{14}$ The Encuesta de Población Activa survey by the National Institute of Statistics provides the number of persons in each group in the quarterly data from the third quarter of 1987 . Thus, $n_{\text {sal }, t}$

\footnotetext{
14 We consider 69 to be the retirement age. The specification of each category of level of education and age is available from the authors upon request.
} 
denotes the number of the working population with sex $(s)$, age $(a)$, and level of education $(l)$ at time $t$.

The second variable needed is the per capita salary of individuals with sex $(s)$, age $(a)$, and level of education $(l)$ at each moment in time $y_{\text {sal, } t}$. This information is provided by the National Institute of Statistics in the Encuesta de Distribución Salarial survey, but is only available for two periods within the years we are sampling: the end of 1995 and the end of 2002. For that reason we assume that the salary within each group grows at a constant quarterly rate and that this rate is computed using the information available about the distribution of salaries into the different categories between these periods. The growth rate in the salary of an individual with sex $(s)$, age $(a)$, and level of education $(l)$ is denoted by $g_{\text {sal }}$. That is,

$$
y_{\mathrm{sal}, t+\tau}=y_{\mathrm{sal}, t}\left(1+g_{\text {sal }}\right)^{\tau}, \quad \tau=0,1, \ldots, 69-t .
$$

Then, the value of the human capital of an individual with sex $(s)$, age $(a)$, and level of education $(l)$ at time $t, h_{\text {sal }, t}$ is computed as

$$
h_{\mathrm{sal}, t}=\sum_{\tau=0}^{L} \frac{y_{\mathrm{sal}, t+\tau}}{(1+r)^{\tau}},
$$

where $L$ is the number of quarters from $t$ to the age of retirement (69), and the discount rate is the average historical excess return of the equally-weighted market index.

Finally, the aggregate value of the human capital at time $t$ is given by

$$
h_{t}=\sum_{s} \sum_{a} \sum_{l} n_{\mathrm{sal}, t} h_{\mathrm{sal}, t} .
$$

\section{References}

Amihud Y, Hurvich C (2004) Predictive regressions: a reduced-bias estimation method. J Financ Quant Anal 39:813-841

Black F (1993) Return and beta. J Portf Manage 20:8-18

Brennan M, Xia Y (2002) Tay's as good as Cay. Anderson School of Management, University of California, Los Angeles

Breusch T (1978) Testing for autocorrelation in dynamic linear models. Aust Econ Pap 17:334-355

Campbell J (1993) Intertemporal asset pricing without consumption data. Am Econ Rev 83:487-512

Campbell J (1996) Understanding risk and return. J Polit Econ 104:298-345

Campbell J, Shiller R (1988) The dividend-price ratio and expectations of future dividends and discount factors. Rev Finance Stud 1:195-228

Capaul C, Rowley I, Sharpe W (1993) International value and growth stock returns. Finance Anal J 49:27-36

Casals J, Jerez M, Sotoca S (2004) Empirical modeling of time series sampled at different frequencies. Working Paper, Universidad Complutense, Madrid

Chan L, Hamao Y, Lakonishok J (1991) Fundamentals and stock returns in Japan. J Finance 46:1739-1764 
Chan L, Jegadeesh N, Lakonishok J (1995) Evaluating the performance of value versus glamour stocks: the impact of selection bias. J Finance Econ 38:269-296

Cochrane J (2001) Asset pricing. Princeton University Press, New Jersey

Cohen R, Polk C, Vuolteenaho T (2001) The value spread. Working Paper no. 8242. National Bureau of Economic Research

Daniel K, Titman S (1997) Evidence on the characteristics of cross sectional variation in stock returns. J Finance 52:1-33

Davis J (1994) The cross-section of realized stock returns: the pre-COMPUSTAT evidence. J Finance 49:1579-1593

Davis JL, Fama EF, French KR (2000) Characteristics, covariances, and average returns: 1929 To 1997. J Finance 55:389-406

DeBondt W, Thaler R (1987) Further evidence on investor overreaction and stock market seasonality. J Finance 42:557-581

Fama E, French K (1988a) Permanent and temporary components of stock prices. J Polit Econ 96:246-273

Fama E, French K (1988b) Dividend yields and expected stock returns. J Finance Econ 22:3-26

Fama E, French K (1993) Common risk factors in the returns on stocks and bonds. J Finance Econ 33:3-56

Fama E, French K (1996) Multifactor explanation of asset pricing anomalies. J Finance 51: 55-84

Fama E, French K (1998) Value versus growth: the international evidence. J Finance 53:1975-1999

Feltham D, Ohlson J (1995) Valuation and clean surplus accounting for operating and financial activities. Contemp Account Res Spring:689-731

Gao P, Huang K (2002) Aggregate consumption/wealth ratio: does it work internationally? Federal Reserve Bank of Kansas City, at http://www.kc.frb.org/publicat/reswkpap/pdf/RWP04-07.pdf

Hodrick R (1992) Dividend yields and expected stock returns: alternative procedures for influence and measurement. Rev Finance Stud 5:357-386

Hodrick R, Zhang X (2001) Evaluating the specification errors of asset pricing models. J Finance Econ 62:327-376

Jagannathan R, Wang Z (1996) The conditional CAPM and the cross-section of expected returns. J Finance 51:3-53

Johansen S (1988) Statistical analysis of cointegration vectors. J Econ Dyn Control 12:231-254

Johansen S (1991) Estimation and hypothesis testing of cointegration vectors in Gaussian vector autoregressive models. Econometrica 59:1551-1580

Keim D, Stambaugh R (1986) Predicting returns in the stock and bond markets. J Finance Econ 17:357-390

Kothari S, Shanken J (1997) Book/market, dividend yield, and expected market returns: a timeseries analysis. J Finance Econ 44:169-203

Lakonishok J, Shleifer A, Vishny R (1994) Contrarian investment, extrapolation and risk. J Finance 49:1541-1578

Lettau M, Ludvigson S (2001a) Consumption, agregate wealth and expected stock returns. J Finance $56: 815-849$

Lettau M, Ludvigson S (2001b) Resurrecting the (C)CAPM: a cross-sectional test when risk premia are time-varying. J Polit Econ 109:1238-1287

Lettau M, Ludvigson S (2001c) Measuring and modeling variation in the risk-return trade off. CEPR Discussion Papers no. 3105

Lettau M, Ludvigson S (2002) Tay's as good as Cay: Reply. Working Paper, Department of Economics, New York University

Lewellen J (2004) Predicting returns with financial ratios. J Financ Econ 74:209-235

Liew J, Vassalou M (2000) Can book/market, size and momentum be risk factors that predict economic growth? J Finance Econ 57:221-245

MacKinlay A (1995) Multifactor models do not explain deviations from the CAPM. J Financ Econ 38:3-28

Newey W, West K (1987) A simple, positive semi-definite, heteroskedasticity and autocorrelation consistent covariance matrix. Econometrica 55:703-708

Nieto B (2002) La Valoración Intertemporal de Activos: Un Análisis Empírico para el Mercado Español de Valores. Investigaciones Económicas 26:497-524 
Ohlson J (1995) Earnings, book values, and dividends in security valuation. Contemp Accoun Res 11:661-687

Pontiff J, Schall L (1999) Book/market ratios as predictors of market returns. J Financ Econ 49:141160

Poterba J, Summers L (1988) Mean reversion in stock prices: evidence and implications. J Financ Econ 22:27-60

Rodríguez R, Restoy F, Peña I (2002) Can output explain the predictability and volatility of stock returns? J Int Money Finance 21:161-183

Rosenberg B, Reid K, Lanstein R (1985) Persuasive evidence of market inefficiency. J Portf Manage 11:9-17

Rudd J, Whelan K (2002) A note on the cointegration of consumption, income, and wealth. Working Paper, Federal Reserve Board, Washington DC

Santos T, Veronesi P (2004) Labour income and predictable stock returns. Rev Financ Stud (in press)

Serrano L, Pastor J (2002) El Valor Económico del Capital Humano. Cuadernos de Capital Humano, IVIE WP2002-24

Stambaugh R (1999) Predictive regressions. J Financ Econ 5:375-421

Vuolteenaho T (2000) Understanding the aggregate book/market ratio. Working Paper, Department of Economics, Harvard University

White H (1980) A heteroskedasticity-consistent covariance matrix estimator and a direct test for heteroskedasticity. Econometrica 48:817-838 